\title{
Work locations in 2014 of medical graduates of Memorial University of Newfoundland: a cross-sectional study
}

\author{
Maria Mathews PhD, Dana Ryan MA, Asoka Samarasena MD \\ See related CMAJ commentary, www.cmaj.ca/lookup/doi/10.1503/cmaj.150266
}

Abstract

Background: Part of the mandate for social accountability of medical schools is to address physician needs at the local, regional and national levels. We determined the work locations in 2014 of medical graduates of Memorial University of Newfoundland (MUN) and identified the characteristics and predictors of working in urban and rural areas of Canada and the province of Newfoundland and Labrador (NL).

Methods: We linked data from class lists, and alumni and postgraduate databases with data from the Scott's Medical Database to determine work locations in 2014 of MUN medical graduates from 1973 to 2008. Multiple logistic regression analysis was used to identify predictors of working in urban and rural areas of Canada and NL.

Results: Of the 1864 graduates in our study, 1642 (88.1\%) were working in Canada, 638 (34.2\%) in NL, 217 (11.6\%) in rural Canada and $92(4.9 \%)$ in rural NL in 2014. Predictors of physicians working in Canada included having a rural background, being from NL and graduating in the 1980s, 1990s or 2000s. Predictors of physicians working in NL included having a rural background, being from $\mathrm{NL}$, graduating in the 2000s and having done some or all of their residency training at MUN. Having a rural background and being a family physician were predictors of working in rural Canada. Having a rural background, being from NL, having done some or all residency training at MUN and being a family physician were predictors of working in rural NL.

Interpretation: Most MUN graduates were working in Canada in 2014, with about one-third remaining in NL and much smaller percentages working in rural communities, especially in rural NL. These findings have implications for the physician supply in NL.

$\mathrm{P}$ art of the mandate for social accountability of medical schools is to address physician workforce needs at the local, regional and national levels. ${ }^{1-3}$ Previously, we examined the work locations in 2004 of medical alumni of Memorial University of Newfoundland (MUN) who graduated between 1973 and 1998 . We found that $86.8 \%$ of alumni were working in Canada, $30.7 \%$ in the province of Newfoundland and Labrador (NL), $12.6 \%$ in rural Canada and 6.1\% in rural NL. ${ }^{4,5}$ We replicated the original study to examine the work locations in 2014 to identify the proportion and predictors of medical graduates working in urban and rural areas of Canada and NL. The study updates information about MUN's contribution to the physician supply in NL and in Canada. Although we focus on 1 medical school, the study provides comparative data to assess the contribution of other medical schools to their regions and to underserved communities.

\section{Methods}

\section{Setting}

The medical school of MUN was established in 1967 to meet the growing demand for physicians, particularly in rural communities.
Currently, it admits 80 students to each class, with 60 seats reserved for students from NL. In 2013, there were 262 (88 firstyear) postgraduate residents. ${ }^{6}$ Physician turnover in NL is high, ${ }^{7,8}$ and shortages are often reported in the media. ${ }^{9}, 10$ Full-time positions for family physicians and specialists are routinely available, especially in smaller communities (Practice Newfoundland and Labrador, www.practicenl.ca/?/jobs/default.asp).

\section{Data collection}

The study was approved by the province's Health Research Ethics Board.

We linked data from class lists, the alumni database and the postgraduate database with data from the Scott's Medical Database (formerly Southam Medical Database). Scott's Medical

\section{Competing interests: None declared.}

This article has been peer reviewed.

Correspondence to: Maria Mathews, mmathews@mun.ca

CMAJ Open 2015. DOI:10.9778/cmajo.20140109 


\section{OPEN}

Database lists physicians in Canada who are members of the Canadian Medical Association and permit release of their information. ${ }^{11}$ The database contains information on physician demographic, training and practice characteristics and work location. As of July 2014, it included $82.5 \%$ of the physicians listed by the College of Physicians and Surgeons of Newfoundland and Labrador (www.cpsnl.ca/default.asp?com=Doctor Search\&adv=1; search date July 31, 2014). We linked data com-

Table 1: Characteristics of 1864 former medical graduates of Memorial University of Newfoundland (MUN) in 2014

\begin{tabular}{|c|c|}
\hline Characteristic & $\begin{array}{c}\text { No. }(\%) \text { of } \\
\text { graduates } \\
n=1864\end{array}$ \\
\hline \multicolumn{2}{|l|}{ Sex } \\
\hline Male & $1008(54.1)$ \\
\hline Female & $856(45.9)$ \\
\hline Rural background & $n=1838$ \\
\hline No & $1318(71.7)$ \\
\hline Yes & $520(27.9)$ \\
\hline From Canada & $n=1849$ \\
\hline No & $83 \quad(4.5)$ \\
\hline Yes & $1766(95.5)$ \\
\hline From NL & $n=1849$ \\
\hline No & $475(25.7)$ \\
\hline Yes & $1374(74.3)$ \\
\hline \multicolumn{2}{|l|}{ Year of graduation } \\
\hline 1973-1979 & $291(15.6)$ \\
\hline $1980-1989$ & 514 (27.6) \\
\hline $1990-1999$ & $546(29.3)$ \\
\hline $2000-2008$ & $513 \quad(27.5)$ \\
\hline Some or all residency training at MUN & $n=1842$ \\
\hline No & $795(43.2)$ \\
\hline Yes & $1047(56.8)$ \\
\hline Specialty & $n=1863$ \\
\hline Specialist & $1057(56.7)$ \\
\hline $\mathrm{FP} / \mathrm{GP}$ & $806(43.3)$ \\
\hline Age at graduation, yr & $n=1853$ \\
\hline$<30$ & $1561(84.2)$ \\
\hline$\geq 30$ & $292(15.7)$ \\
\hline \multicolumn{2}{|l|}{ Workplace in Canada } \\
\hline No & $222(11.9)$ \\
\hline Yes & $1642(88.1)$ \\
\hline \multicolumn{2}{|l|}{ Workplace in NL } \\
\hline No & $1226(65.8)$ \\
\hline Yes & $638(34.2)$ \\
\hline \multicolumn{2}{|l|}{ Workplace in rural Canada } \\
\hline No & $1647(88.4)$ \\
\hline Yes & $217(11.6)$ \\
\hline \multicolumn{2}{|l|}{ Workplace in rural NL } \\
\hline No & $1772(95.1)$ \\
\hline Yes & $92 \quad(4.9)$ \\
\hline
\end{tabular}

mon to each data source (first and last names, maiden names, sex and year of graduation). Names were removed from the dataset before analysis.

Our sample frame included all MUN medical alumni who graduated from 1973 (the first year medical students graduated from the university) to 2008. We selected 2008 as the cut-off year to allow sufficient time for graduates to complete their residency training and enter practice. We reviewed the alumni database and Scott's Medical Database and excluded deceased and retired physicians; military physicians because they may have limited ability to choose their work location; and students who were sponsored by the Malaysian government and were required to return home after completing their training. We also reviewed publications (e.g., MUN alumni magazines) to identify deceased and retired physicians.

We considered 4 outcomes related to physicians' work locations in 2014: working in Canada (yes/no); working in NL (yes/ no); working in rural Canada (yes/no); and working in rural NL (yes/no). Physicians' locations were based on work addresses reported in the Scott's Medical Database and, if unreported, in the alumni database. Both databases are updated when new information is received. For this study, we used work locations reported in July 2014.

We categorized communities as urban ( $\geq 10000$ population) or rural (<10 000 population) based on the 2001 census population; bedroom communities were included as part of larger urban centres, based on Statistics Canada's metropolitan influenced zone (MIZ) scores. ${ }^{12}$ We used the 2001 census population and the cut-off population of 10000 for rural communities to be consistent with our earlier study. ${ }^{5}$ The cutoff is relevant to NL, where regional centres have populations greater than 10000 . Community size was verified using the Statistics Canada 2001 community profiles. ${ }^{13}$

We examined the influence of the following predictor variables on work location in 2014: sex, residence background (rural v. urban), hometown location (Canada v. elsewhere, and NL v. elsewhere), decade of graduation (1970s, 1980s, 1990s or 2000s), location of residency training (some or all residency training at MUN v. elsewhere), specialty (family physician v. specialist) and age at graduation (<30 yr v. $\geq 30 \mathrm{yr})$. Hometowns reported at the time of school admission and included on graduating class lists were used to determine whether graduates were from Canada, from NL and from a rural community (hometown population < 10 000). Specialty was based on the physician's certified specialization as recorded in the Scott's Medical Database or alumni database. We categorized each physician as either a family physician (general practitioner or family medicine specialist) or a specialist.

\section{Statistical analysis}

We performed all analyses using IBM SPSS Statistics software (version 20.0; IBM). After describing the characteristics of the sample using frequencies, we used $\chi^{2}$ tests to identify differences between each outcome and the predictor variables, and multiple logistic regression analysis to identify significant $(p<0.05)$ predictors for each outcome. Potential predictors for each regression model were selected on the basis of the 
bivariate analyses. Colinearity between predictor variables was examined a priori.

\section{Results}

Of the 2099 physicians who had graduated from MUN from 1973 to 2008, we excluded 48 who were deceased, 10 who were retired, 19 who were sponsored by the Malaysian government and 158 whose work location in 2014 was unknown. This left 1864 graduates in the study sample. Compared with the study sample, a significantly larger proportion of physicians whose 2014 work location was unknown were female $(57.0 \%$ v. $45.9 \%$, $p=0.008)$, were not from Canada $(9.6 \%$ v. $4.5 \%, p=0.004)$, were not from NL (34.6\% v. $25.7 \%, p=0.02)$, and graduated in the 1970 s $(25.8 \%$ v. $15.6 \%, p=0.04)$ and 2000 s $(40.3 \%$ v. $27.5 \%, p=0.04$ ) (data not shown).
The majority of the medical graduates in our study were male $(54.1 \%)$, came from an urban background $(71.7 \%)$, were from Canada (95.5\%), were from NL specifically (74.3\%), did some or all of their residency training at MUN (56.8\%), were specialists $(56.7 \%)$ and were less than 30 years old when they graduated $(84.2 \%)$ (Table 1$)$. The mean age at graduation was 26.5 years. The majority $(88.1 \%)$ were working in Canada in 2014. Over one-third of the graduates $(34.2 \%)$ were working in NL, $11.6 \%$ in rural Canada and $4.9 \%$ in rural NL.

Compared with those working outside Canada, a significantly larger proportion of graduates working in Canada were female, from rural backgrounds, from Canada, from NL, had graduated in the 1990s, and had done some or all of their residency training at MUN (Table 2). After controlling for other significant predictors in the logistic regression analysis, we found that having a rural background, being from NL and

Table 2: Characteristics of graduates who were working in and outside Canada, and in and outside NL in 2014

\begin{tabular}{|c|c|c|c|c|c|c|}
\hline \multirow[b]{2}{*}{ Characteristic } & \multicolumn{2}{|c|}{ No. (\%) of graduates } & \multirow[b]{2}{*}{$p$ value } & \multicolumn{2}{|c|}{ No. $(\%)$ of graduates } & \multirow[b]{2}{*}{$p$ value } \\
\hline & $\begin{array}{l}\text { Working outside } \\
\text { Canada } \\
n=222\end{array}$ & $\begin{array}{l}\text { Working in Canada } \\
\qquad n=1642\end{array}$ & & $\begin{array}{l}\text { Working } \\
\text { outside NL } \\
n=1226\end{array}$ & $\begin{array}{l}\text { Working } \\
\text { in NL } \\
n=638\end{array}$ & \\
\hline Sex & & & 0.01 & & & 0.2 \\
\hline Male & $138(62.2)$ & $870(53.0)$ & & $676(55.1)$ & $332(52.0)$ & \\
\hline Female & 84 (37.8) & $772(47.0)$ & & $550(44.9)$ & $306(48.0)$ & \\
\hline Rural background & $n=220$ & $n=1619$ & 0.002 & $n=1205$ & $n=634$ & $<0.001$ \\
\hline No & $173(78.6)$ & $1106(68.3)$ & & $890(73.9)$ & $389(61.4)$ & \\
\hline Yes & $47(21.4)$ & $513(31.7)$ & & $315(26.1)$ & $245(38.6)$ & \\
\hline From Canada & $n=221$ & $n=1628$ & $<0.001$ & $n=1216$ & $n=633$ & $<0.001$ \\
\hline No & $56(25.3)$ & $27 \quad(1.7)$ & & $79 \quad(6.5)$ & $4 \quad(0.6)$ & \\
\hline Yes & $165(74.7)$ & $1601(98.3)$ & & 1137 (93.5) & $629(99.4)$ & \\
\hline From NL & $n=221$ & $n=1628$ & $<0.001$ & $n=1215$ & $n=634$ & $<0.001$ \\
\hline No & $98(44.3)$ & $377(23.2)$ & & $447(36.8)$ & $28 \quad(4.4)$ & \\
\hline Yes & $123(55.7)$ & $1251(76.8)$ & & $768(63.2)$ & $606(95.6)$ & \\
\hline Year of graduation & & & 0.006 & & & $<0.001$ \\
\hline 1973-1979 & $50(22.5)$ & $241(14.7)$ & & $196(16.0)$ & 95 (14.9) & \\
\hline 1980-1989 & $64(28.8)$ & $450(27.4)$ & & $361(29.4)$ & $153(24.0)$ & \\
\hline 1990-1999 & $49(22.1)$ & $497(30.3)$ & & $371(30.3)$ & $175(27.4)$ & \\
\hline $2000-2008$ & $59(26.6)$ & $454(27.6)$ & & $298(24.3)$ & $215(33.7)$ & \\
\hline $\begin{array}{l}\text { Some or all residency } \\
\text { training at MUN }\end{array}$ & $n=221$ & $n=1621$ & $<0.001$ & $n=1210$ & $n=632$ & $<0.001$ \\
\hline No & $120(54.3)$ & $675(41.6)$ & & $671(55.5)$ & $124(19.6)$ & \\
\hline Yes & $101(45.7)$ & $946(58.4)$ & & $539(44.5)$ & $508(80.4)$ & \\
\hline Specialty & & $n=1641$ & 0.5 & $n=1225$ & & 0.01 \\
\hline Specialist & $131(59.0)$ & $926(56.4)$ & & $720(58.8)$ & $337(52.8)$ & \\
\hline GP/FP & $91(41.0)$ & $715(43.6)$ & & 505 (41.2) & 301 (47.2) & \\
\hline Age at graduation, yr & $n=221$ & $n=1632$ & 0.4 & $n=1221$ & $n=632$ & 0.9 \\
\hline$<30$ & $182(82.4)$ & $1379(84.5)$ & & $1028(84.2)$ & $533(84.3)$ & \\
\hline$\geq 30$ & $39(17.6)$ & $253(15.5)$ & & $193(15.8)$ & $99(15.7)$ & \\
\hline
\end{tabular}


Table 3: Factors predicting whether graduates were working in Canada, in NL, in rural Canada and in rural NL in 2014

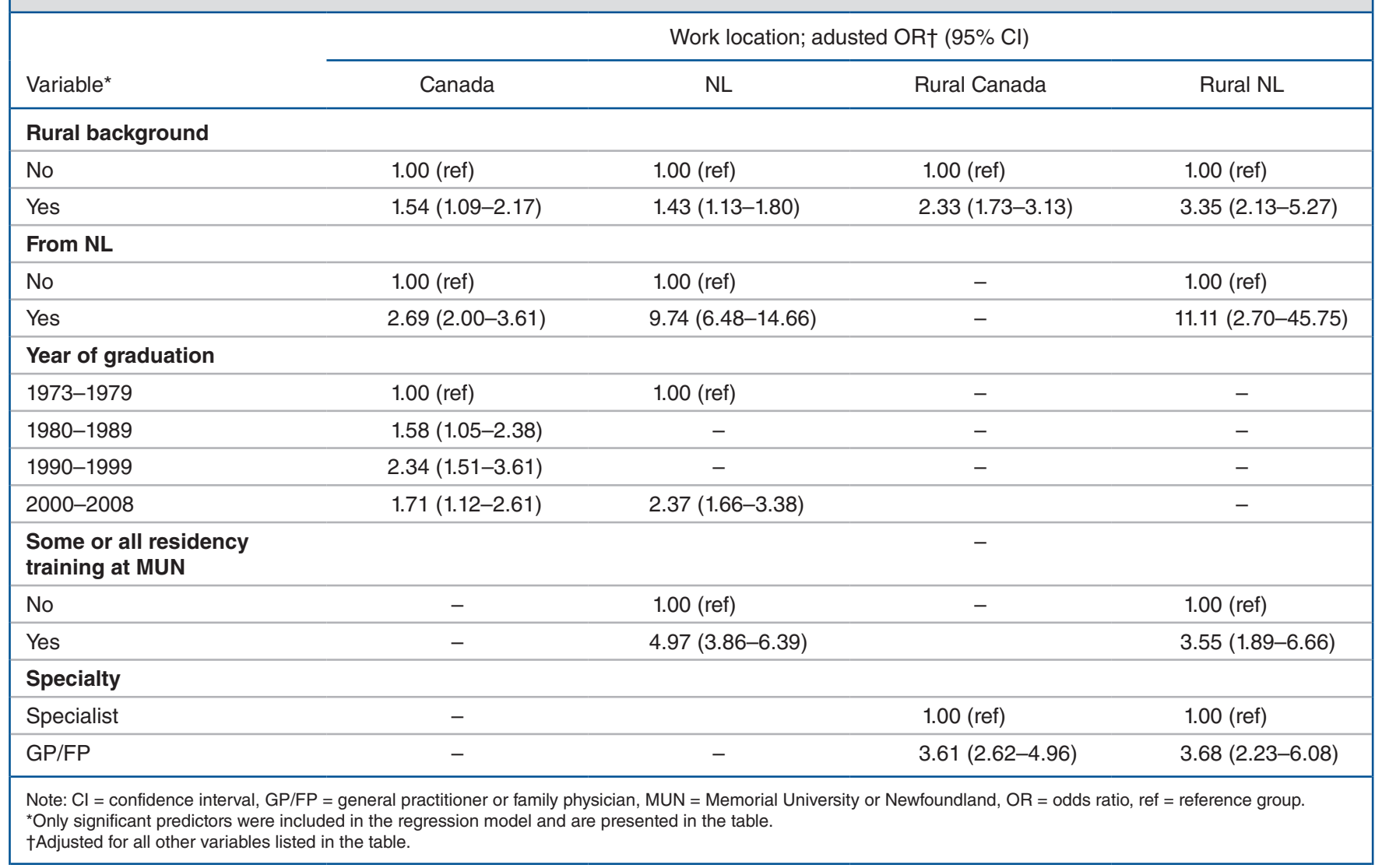

graduating after 1979 were significant predictors of working in Canada (Table 3).

Compared with the graduates working outside NL, a significantly larger proportion of graduates working in NL had a rural background, were from Canada, were from NL, graduated in the 2000s and had done some or all of their residency training at MUN (Table 2). After controlling for other significant predictors in the logistic regression analysis, we found that having a rural background, being from NL, graduating in the 2000s and having done some or all of their residency training at MUN were significant predictors of working in NL (Table 3).

Compared with the graduates working in urban communities in Canada, a significantly larger proportion of those working in rural Canada had a rural background, graduated in the 1970 s or 1990s, had done some or all of their residency training at MUN and were family physicians (Table 4). After controlling for other significant predictors, we found that having a rural background and being a family physician were significant predictors of working in rural Canada (Table 3).

Compared with the graduates working in urban communities in NL, a significantly larger proportion of those working in rural NL had a rural background, were from Canada, were from NL, completed some or all of their residency training at MUN and were family physicians (Table 4). After controlling for other significant predictors in the logistic regression analysis, we found that having a rural background, being from NL, having done some or all of their residency training at MUN and being a family physician were significant predictors of working in rural NL (Table 3).

\section{Interpretation}

In our cross-sectional study of work locations in 2014 of MUN medical school graduates from 1973 to 2008, we found that most $(88.1 \%)$ of the alumni were working in Canada, with about one-third remaining in NL; smaller percentages were in rural practice in Canada (11.6\%) and NL $(4.9 \%)$. These proportions differed slightly from those we observed in $2004,{ }^{4,5}$ with a drop in the proportion of alumni working in Canada, rural Canada and rural NL, and an increase in the proportion working in NL overall.

Most $(88.4 \%)$ of the MUN graduates were working in urban centres in 2014, which is consistent with findings from other studies. ${ }^{14,15}$ In one study, $16 \%$ of graduates from Canadian medical schools were practising in rural communities. ${ }^{14}$ The majority (85.6\% [546/638]) of MUN graduates working in NL were working in urban centres, which is not surprising given the growing number of alumni working as specialists in the province. Rural communities are unlikely to be large enough to support various specialties. In 2014, there were 92 physicians working in rural NL, a net gain of 11 physicians since $2004 .^{5}$ In 2004, MUN medical graduates made up roughly $20.8 \%$ of the rural physician workforce in $\mathrm{NL}^{5}$ in 2014, they made up 20.9\% (based on data from the College of 
Table 4: Characteristics of graduates who were working in and outside of rural communities in Canada and NL in 2014

\begin{tabular}{|c|c|c|c|c|c|c|}
\hline \multirow[b]{2}{*}{ Characteristic } & \multicolumn{2}{|c|}{ No. $(\%)$ of graduates } & \multirow[b]{2}{*}{$p$ value } & \multicolumn{2}{|c|}{ No. $(\%)$ of graduates } & \multirow[b]{2}{*}{$p$ value } \\
\hline & $\begin{array}{l}\text { Working outside } \\
\text { rural Canada } \\
\quad n=1647\end{array}$ & $\begin{array}{l}\text { Working in } \\
\text { rural Canada } \\
n=217\end{array}$ & & $\begin{array}{l}\text { Working outside } \\
\text { rural NL } \\
n=1772\end{array}$ & $\begin{array}{c}\text { Working in } \\
\text { rural NL } \\
n=92\end{array}$ & \\
\hline Sex & & & 0.09 & & & 0.3 \\
\hline Male & $879(53.4)$ & $129(59.4)$ & & $953(53.8)$ & 55 (59.8) & \\
\hline Female & $768(46.6)$ & $88(40.6)$ & & $819(46.2)$ & 37 (40.2) & \\
\hline Rural background & $n=1627$ & $n=212$ & $<0.001$ & $n=1747$ & & $<0.001$ \\
\hline No & $1174(72.2)$ & $105(49.5)$ & & $1246(71.3)$ & $33(35.9)$ & \\
\hline Yes & $453(27.8)$ & $107(50.5)$ & & $501(28.7)$ & $59(64.1)$ & \\
\hline From Canada & $n=1635$ & $n=214$ & 0.049 & $n=1757$ & & 0.03 \\
\hline No & $79 \quad(4.8)$ & $4 \quad(1.9)$ & & $83 \quad(4.7)$ & 0 & \\
\hline Yes & $1556(95.2)$ & $210(98.1)$ & & $1674(95.3)$ & $92(100.0)$ & \\
\hline From NL & $n=1635$ & $n=214$ & 0.3 & $n=1757$ & & $<0.001$ \\
\hline No & $426(26.1)$ & $49(22.9)$ & & $473(26.9)$ & $2 \quad(2.2)$ & \\
\hline Yes & $1209(73.9)$ & $165(77.1)$ & & $1284(73.1)$ & $90(97.8)$ & \\
\hline Year of graduation & & & 0.02 & & & 0.08 \\
\hline 1973-1979 & $253(15.4)$ & 38 (17.5) & & $271(15.3)$ & 20 (21.7) & \\
\hline 1980-1989 & $458(27.8)$ & $56(25.8)$ & & $496(28.0)$ & $18(19.6)$ & \\
\hline 1990-1999 & $467(28.4)$ & 79 (36.4) & & $513(29.0)$ & 33 (35.9) & \\
\hline 2000-2008 & $469(28.5)$ & $44(20.3)$ & & $492(27.8)$ & $21(22.8)$ & \\
\hline $\begin{array}{l}\text { Some or all residency } \\
\text { training at MUN }\end{array}$ & $n=1628$ & $n=214$ & 0.003 & $n=1750$ & & $<0.001$ \\
\hline No & $723(44.4)$ & $72(33.6)$ & & $783(44.7)$ & $12(13.0)$ & \\
\hline Yes & $905(55.6)$ & $142(66.4)$ & & 967 (55.3) & $80(87.0)$ & \\
\hline Specialty & $n=1646$ & & $<0.001$ & $n=1771$ & & $<0.001$ \\
\hline Specialist & $994(60.4)$ & $63(29.0)$ & & $1035(58.4)$ & $22(23.9)$ & \\
\hline GP/FP & $652(39.6)$ & $154(71.0)$ & & $736(41.6)$ & $70(76.1)$ & \\
\hline Age at graduation, yr & $n=1637$ & $n=216$ & 0.6 & $n=1761$ & & 0.9 \\
\hline$<30$ & $1382(84.4)$ & $179(82.9)$ & & $1484(84.3)$ & $77(83.7)$ & \\
\hline$\geq 30$ & $255(15.6)$ & $37(17.1)$ & & $277(15.7)$ & $15(16.3)$ & \\
\hline
\end{tabular}

Physicians and Surgeons of Newfoundland and Labrador [www.cpsnl.ca/default.asp?com=DoctorSearch\&adv=1; search date 2014 July 31]). Whereas MUN graduates accounted for the majority of the NL physician workforce in 2014, physicians in the province's rural communities continued to be largely international medical graduates and graduates from other Canadian medical schools.

Compared with work locations in $2004,4,5$ the proportions of MUN medical graduates working in Canada overall, and in rural communities in Canada and NL were lower in 2014, whereas the proportion of graduates working in NL overall was higher in 2014. Between 2004 and 2012 (the year with the most recently available data from the Canadian Institute for Health Information [CIHI]), the number of physicians in NL grew from 992 (192 per 100000 population) to 1152 (240 per 100 000). ${ }^{16,17}$ The MUN medical graduates comprised $55.4 \%$
(638/1152) of the provincial workforce in 2014 , an increase from $40.9 \%$ (406/992) in 2004. These figures bode well for long-term retention given that MUN-trained physicians have longer retention times in NL than other Canadian or international medical graduates. ${ }^{5,7,8}$

\section{Limitations}

Our study relied on administrative data, which do not capture the full range of factors that may affect decisions about work location. Our results may underestimate the number of recent graduates in each location, because new graduates were overrepresented among alumni excluded for not having a work location in 2014. We also made multiple comparisons, which increased the risk of a type 1 error. The study was cross-sectional and provided data on work location at one point in time and did not estimate the length of time a physician worked in 
a given location. It also included physicians at different stages of their careers. Also, the study looked at 1 medical school and 1 province; further research is needed to produce comparable studies from other provinces. The results of this study may not apply to other jurisdictions.

\section{Conclusion}

Most MUN graduates were working in Canada in 2014, with about one-third remaining in NL and much smaller percentages working in rural communities, especially in rural NL. These findings have implications for the physician supply in NL.

\section{References}

1. Stoddart GL, Barer ML. Toward integrated medical resource policies for Canada: 5. The roles and funding of academic medical centres. CMAf 1992;146:1919-24.

2. Strasser R, Neusy AJ. Context counts: training health workers in and for rural and remote areas. Bull World Health Organ 2010;88:777-82.

3. Curran V, Rourke J. The role of medical education in the recruitment and retention of rural physicians. Med Teach 2004;26:265-72.

4. Mathews M, Rourke JTB, Park AD. National and provincial retention of medical graduates of Memorial University. CMA7 2006;175:357-60.

5. Mathews M, Park AD, Rourke JTB. The contribution of Memorial University's medical school to rural physician supply. Can 7 Rural Med 2008;13:15-21.

6. Canadian Post-M.D. Education Registry 2013-2014: Newfoundland provincial report. Ottawa: Canadian Post-M.D. Education Registry; 2014. Available: www.caper.ca/ assets/pdf_2013ProvReport_NF.pdf (accessed 2015 Apr. 7).

7. Fleming $\mathrm{P}$, Mathews $M$. Retention of specialist physicians in Newfoundland and Labrador. Open Med 2012;6:e1-9.

8. Audas R, Ryan A, Vardy D. Where did the doctors go? A study of retention and migration of provisionally licensed international medical graduates practising in Newfoundland and Labrador between 1995 and 2006. Can 7 Rural Med 2009;14:21-4.

9. Doctor shortage on Burin Peninsula worrisome for patients. Toronto: CBC News; 2014. Available: www.cbc.ca/news/canada/newfoundland-labrador/doctor -shortage-on-burin-peninsula-worrisome-for-patients-1.2758070 (accessed 2015 Apr. 7).

10. Doctor shortage alleviated in Grand Falls-Windsor. Toronto: CBC News; 2013. Available: www.cbc.ca/news/canada/newfoundland-labrador/doctor -shortage-alleviated-in-grand-falls-windsor-1.1379335 (accessed 2015 Apr. 7).

11. Select MD. MD Select user's manual. Toronto: Business Information Group 2004.

12. Census metropolitan influenced zone (MIZ). Ottawa: Statistics Canada; 2011 Available: www12.statcan.gc.ca/census-recensement/2011/ref/dict/geo010-eng. cfm (modified 2012 Dec. 4; accessed 2015 Apr. 7)

13. 2001 community profiles. Ottawa: Statistics Canada; 2011. Available: www12. statcan.ca/english/profil01/CP01/Index.cfm?Lang=E (accessed 2015 Apr. 7).

14. Buske L. First practice: family physicians initially locating in rural areas. Can 7 Rural Med 2013;18:80-5.

15. Lu DJ, Hakes J, Bai M, et al. Rural intentions - factors affecting the career choices of family medicine graduates. Can Fam Physician 2008;54:1016-7.e5.

16. Supply, distribution and migration of Canadian physicians, 2012. Ottawa: Canadian Institute for Health Information; 2013

17. Supply, distribution and migration of Canadian physicians, 2008. Ottawa: Canadian Institute for Health Information; 2009.

Affiliations: Division of Community Health and Humanities, Faculty of Medicine (Mathews, Ryan); Postgraduate Medical Education, Faculty of Medicine (Samarasena), Memorial University of Newfoundland, St. John's, Nfld.

Contributors: Maria Mathews conceived and designed the study, supervised data linkage and analysis, interpreted the findings and wrote the first draft of the manuscript. Dana Ryan performed the data linkage and analysis, prepared data tables, helped interpret the findings and helped write the first draft of the manuscript. Asoka Samarasena assisted with data acquisition, reviewed the analysis, helped interpret the findings, provided secondary sources to confirm study interpretations and helped revise the manuscript. All of the authors approved the version to be published and agreed to act as guarantors of the work.

Supplemental information: For reviewer comments and the original submission of this manuscript, please see www.cmajopen.ca/content/3/2/ E217/suppl/DC1 